\title{
The spatial distribution of region 2 field-aligned currents relative to subauroral polarization stream
}

\author{
H. Wang ${ }^{1,2}$, H. Lühr ${ }^{3}$, A. Ridley ${ }^{4}$, and T. Huang ${ }^{1}$ \\ ${ }^{1}$ Dept. of Space Physics, School of Electronic Information, Wuhan University, Wuhan 430072, P. R. China \\ ${ }^{2}$ State Key Laboratory of Space Weather, Chinese Academy of Sciences, Beijing, 100190, China \\ ${ }^{3}$ Helmholtz Centre Potsdam-GFZ, German Research Center for Geosciences, 14473 Potsdam, Germany \\ ${ }^{4}$ Department of Atmospheric, Oceanic, and Space Sciences, University of Michigan, Ann Arbor, MI-48109, USA \\ Correspondence to: H. Wang (h.wang@whu.edu.cn)
}

Received: 8 January 2014 - Revised: 4 April 2014 - Accepted: 11 April 2014 - Published: 22 May 2014

\begin{abstract}
To test the current-generation model of subauroral polarization stream (SAPS), we have investigated the relative positions of field-aligned currents (FACs) with respect to SAPS in a statistical way by using CHAMP (CHAllenging Minisatellite Payload) and DMSP (Defense Meteorological Satellite Program) satellite observations as well as model simulations. Comparative studies have been performed for consecutive CHAMP observations in different magnetic local time (MLT) sectors with respect to SAPS. The latitude of the peak westward zonal wind deduced from CHAMP measurements has been used to represent the location of the SAPS peak. Both the density and the sheet current strength of R2 (region 2) FACs are enhanced when SAPS occur. Subsequently R2 FACs decay in intensity and correspondingly the centers retreat poleward. The latitudes of the center of the R2 FAC, small- and medium-scale FACs, and SAPS shift equatorward with increasing MLT. The SAPS peaks are located between R2 and R1 (region 1) FAC peaks in all MLT bins under study. The SAPS peaks are closer to R2 centers in the later MLT sectors. The peaks of small- and mediumscale FACs are located poleward of SAPS, mainly in the upward R1 FACs region. The upward R1 FACs are partly closed by the downward R1 FACs in the dawn-morning sector. Based on model simulation, when R2 shifts equatorward to the subauroral region, the plasma flow also shifts equatorward with its peak located poleward of that of R2 FACs. Both the model and observations provide evidence that SAPS behave as caused by a magnetospheric current source.
\end{abstract}

Keywords. Ionosphere (electric fields and currents; ionosphere-magnetosphere interactions) - magnetospheric physics (current systems)

\section{Introduction}

The subauroral polarization stream (SAPS) is one of the interesting and important features of the magnetosphereionosphere-thermosphere coupling processes in the subauroral region, representing the rapid westward plasma flow predominantly in the dusk and premidnight sector (16-24 magnetic local time, MLT) (e.g., Galperin et al., 1974; Spiro et al., 1979; Anderson et al., 1991, 1993, 2001; Yeh et al., 1991; Fejer and Scherliess, 1998; Scherliess and Fejer, 1998; Rowland and Wygant, 1998; Wygant et al., 1998; Ridley et al., 2002; Foster et al., 2002; Foster and Vo, 2002; Garner et al., 2004; Figueiredo et al., 2004; Liemohn et al., 2005; Jensen and Fejer, 2007; Zheng et al., 2008; Erickson et al., 2010, 2011; Clausen et al., 2012; Mishin, 2013). Two types of plasma flows have been classified in the literature: (1) polarization jets (PJ) (Galperin et al., 1974) or subauroral ion drifts (SAIDS) (Spiro et al., 1979), featured as more intense $\left(\sim 1000 \mathrm{~m} \mathrm{~s}^{-1}\right)$ and latitudinally confined $\left(\leq 1^{\circ}\right.$ latitude) plasma flow; and (2) a wider latitudinal extent and longer duration of plasma flow (Yeh et al., 1991). In the present study we are referring to both types.

By using satellite and radar observations as well as model simulations, previous studies have shown that SAPS have great impacts on the ionosphere. SAPS can deepen the F region trough density (e.g., Smiddy et al., 1977; Maynard, 1978; Spiro et al., 1978; Anderson et al., 1991, 2001; Foster et al., 2007), enhance the electron temperature (e.g., Wang and Lühr, 2013; Mishin, 2013), contribute to the ion upflow (e.g., Yeh and Foster, 1990; Anderson et al., 1991; Moffett et al., 1992; Erickson et al., 2010; Wang and Lühr, 2013), and 
induce strong scintillations of UHF (ultra-high frequency) and L-band signals (e.g., Basu et al., 2008). Recent studies have disclosed that SAPS can cause westward wind jets and air density anomalies, which peak at the same location (e.g., Wang et al., 2012a, b; Wang et al., 2012).

SAPS behave either like a voltage or current source in the inner magnetosphere. The anticorrelation between the width and the peak intensity of SAPS might suggest a voltage source (Figueiredo et al., 2004; Kunduri et al., 2012). The outward SAPS electric field forms when the inner boundary of the hot ion plasma sheet moves further earthward of the electron boundary. An alternative idea is that the SAPS electric field originates in the voltage difference between the cold-trough plasma and the hot plasma injected from the magnetotail (De Keyser, 1999).

The strong correlation between the ionospheric conductivity and SAPS latitude, in particular the anticorrelation between the conductivity and SAPS velocity might suggest a current-source mechanism (e.g., Anderson et al., 1993, 2001; Figueiredo et al., 2004; Wang et al., 2008). In this theory region 2 (R2) field-aligned currents (FACs) flowing into the ionosphere in the dusk-premidnight sector, feed the poleward Pedersen currents through the less-conductive subauroral region, and flow out of the ionosphere in the auroral region as R1 (region 1) FACs. Harel et al. (1981) found an enhanced SAPS in direct association with intense R2 FACs. Karlsson et al. (1998) found that the strongest SAPS occur in that MLT sector when FACs are most intense. These findings are in support of the current-source model. The alternative explanation to the above is that the center of a SAPS should be located between the large-scale R2 and R1 FACs.

However, recent works (e.g., Mishin, 2013) have reported that R2 FACs are concentrated near the poleward boundary of SAPS and do not enclose the channel, which is inconsistent with the current-generator theory. Alternatively they have proposed another concept that a SAPS is a turbulent plasmaspheric boundary layer via a short circuiting of the plasmoid within the ambient plasma in the plasmasphere (e.g., Mishin, 2013). Enhanced plasma waves within the SAPS channel lead to anomalous circuit resistivity and magnetic diffusion, as in the plasmoid-magnetic barrier problem.

The spatial distribution of SAPS relative to the magnetospheric and ionospheric parameters, such as precipitation boundary layers, have been studied statistically in the literature. SAPS is located closely to the transition region from $\mathrm{H}^{+}$- to $\mathrm{O}^{+}$-dominant plasma (Rich et al., 1980). The model predicts that SAPS occur in the region between the proton's inner edge and the electron's precipitation edge (Southwood and Wolf, 1978). SAPS is located poleward of the reduced Pedersen conductivity (Figueiredo et al., 2004). However, a statistical study of the relative position of FACs with respect to the SAPS is lacking so far. In this paper we will present a statistical study of the spatial distribution of FACs relative to SAPS by using both CHAMP (CHAllenging Minisatellite Payload) and DMSP (Defense Meteorological Satellite
Program) observations from 2002 to 2003 to fill the gap in the literature. The study will contribute to a further understanding of physical processes occurring in the subauroral region. In the following section we briefly describe the method of data processing. Section 3 describes the statistical result. In the discussion section we compare results with previous reports and provide explanations.

\section{Data sets}

\subsection{CHAMP orbit and observation}

CHAMP has a near-polar $\left(87.3^{\circ}\right.$ inclination) orbit with an initial altitude of $\sim 450 \mathrm{~km}$ with a period of $93 \mathrm{~min}$ (Reigber et al., 2002). During 2002 and 2003 the altitude was $\sim 400 \mathrm{~km}$ on average. The orbit covers all local times within 130 days ( $\sim 4$ months). CHAMP comprises a fluxgate magnetometer (FGM), which delivers vector field readings at a rate of $50 \mathrm{~Hz}$ and a resolution of $0.1 \mathrm{nT}$. The data are calibrated with respect to the onboard absolute scalar Overhauser magnetometer. The orientation of the field vectors are provided by a dual-head star camera system mounted together with the FGM on an optical bench. Data used in this study are the $1 \mathrm{~Hz}$ preprocessed vector data in the north-east-center frame, which is a localized coordinate system with $x$ axis pointing to geographical north, the $z$ axis is pointing downward to Earth's center and, and the $y$ axis completes the orthogonal coordinate system, pointing to the geographical east.

The FAC density is determined according to Ampere's law from the vector magnetic field data by solving the $\operatorname{curl} B$, that is, $j_{z}=\frac{1}{\mu_{0}}\left(\frac{\partial B_{y}}{\partial x}-\frac{\partial B_{x}}{\partial y}\right)$, where $\mu_{0}$ is the vacuum permeability, $B_{x}$ and $B_{y}$ are the transverse magnetic field deflections caused by the electric currents in the $z$ direction. We have assumed that FACs are infinite sheets aligned with the mean location of the auroral oval (Wang et al., 2005). Since we do not have multipoint measurements, we convert the observed temporal variation into spatial gradients by considering the spacecraft's velocity under the assumption of stationarity of the current during the time of satellite passage (55$75^{\circ}$ MLat), which is around $5 \mathrm{~min}$. After discrete sampling is introduced (Lühr et al., 1996) we obtain $j_{z}=\frac{1}{\mu_{0} v_{x}} \frac{\Delta B_{y}}{\Delta t}$, where $v_{x}$ is the velocity perpendicular to the current sheet and $B_{y}$ is the magnetic deflection parallel to the sheet. We have investigated the spatial distribution of FACs in response to the solar wind and geomagnetic activity previously (e.g., Wang et al., 2005, 2006, 2008).

\subsection{DMSP orbit and observation}

The DMSP orbital period is approximately $100 \mathrm{~min}$ and the altitude is $\sim 835 \mathrm{~km}$. The satellites have fixed local times with F13 in the near-dawn-dusk sector and F15 in the dayside-nightside (9-21 MLT) local time sector. The 
ion-drift meter (IDM) can provide ion-drift velocities in both horizontal and vertical directions perpendicular to the satellite orbit (Rich and Hairston, 1994). The average energy flux of electrons and ions in the range of $30 \mathrm{eV}$ to $30 \mathrm{keV}$ are monitored by the DMSP electron spectrometer (SSJ/4) instruments (Hardy et al., 1984). We use an empirical relationship between the average electron energy flux and the heightintegrated ionospheric conductivity (Robinson et al., 1987) to determine the poleward boundary of the subauroral region. SAPS are defined as rapid sunward (westward) plasma flows greater than $100 \mathrm{~m} \mathrm{~s}^{-1}$ in the subauroral and premidnight region, which have been identified in a similar way as described by Wang et al. (2008). DMSP passes with angles between the orbit track and the auroral oval of less than $45^{\circ}$ have been discarded to guarantee that the DMSP cross-track direction is approximately aligned with the auroral oval. We have handled repeated SAPS observations in subsequent orbits as one event. The key time and magnetic-latitude marks the SAPS velocity peak (Wang et al., 2012b). The plasma velocities and the FACs density data are all presented in the apex magnetic coordinate system (e.g., Richmond, 1995).

In order to obtain a comprehensive picture of the spatial distributions of FACs, we have grouped CHAMP orbits into three $2 \mathrm{~h}$ MLT bins extending from $2 \mathrm{~h}$ in MLT before the SAPS-detection location to $4 \mathrm{~h}$ in MLT past it. The grouping is performed separately for F13 and F14/15 SAPS events because they are flying in different MLT planes. Bin 1 contains CHAMP passes to the west of a SAPS (from MLT $_{\text {SAPS }}-2 \mathrm{~h}$ to MLT $_{\text {SAPS }}$ ), bin 2 to the east (from MLT $_{\text {SAPS }}$ to MLT $_{\text {SAPS }}+2 \mathrm{~h}$ ), and bin 3 between 2 and $4 \mathrm{~h}$ east in MLT (from MLT SAPS $+2 \mathrm{~h}$ to MLT $_{\text {SAPS }}+4 \mathrm{~h}$ ). To understand the temporal evolution of FACs, we have considered four consecutive CHAMP orbits within a time window of $1.5 \mathrm{~h}$ before and $3 \mathrm{~h}$ after the detection time of a SAPS. The orbits passing the MLat (magnetic latitude) of the SAPS peak velocity about 0-30 min after the SAPS key time are declared as concurrent orbits. The orbits $1.5 \mathrm{~h}$ before the events are regarded as previous orbits. The orbits 1.5 and $3 \mathrm{~h}$ later are thought of as after-event passes. The same approach has been utilized to study the temporal and spatial effect of SAPS on the thermospheric dynamics (Wang et al., 2012b).

As an example, Fig. 1 shows the latitudinal variation of electrodynamic parameters in the dusk sector coordinately observed by CHAMP and DMSP F13 over the northern middle-high-latitude region. The upper plot shows the ionospheric polar footprints of both satellites. CHAMP flies through the region around the same time as DMSP's detection of a SAPS peak, but about $1 \mathrm{~h}$ to the east in MLT, thus classified as a bin 2 orbit. Figure 1 shows the latitude profile of the Pedersen conductivity derived from the particle precipitation, ionospheric convection in the east and west direction, and field-aligned current in the bottom panel. Positive values represent eastward (upward) direction for the convection velocity (FACs) in the dusk sector. Equatorward of the auroral oval, indicated by the strong particle precipitation, one can
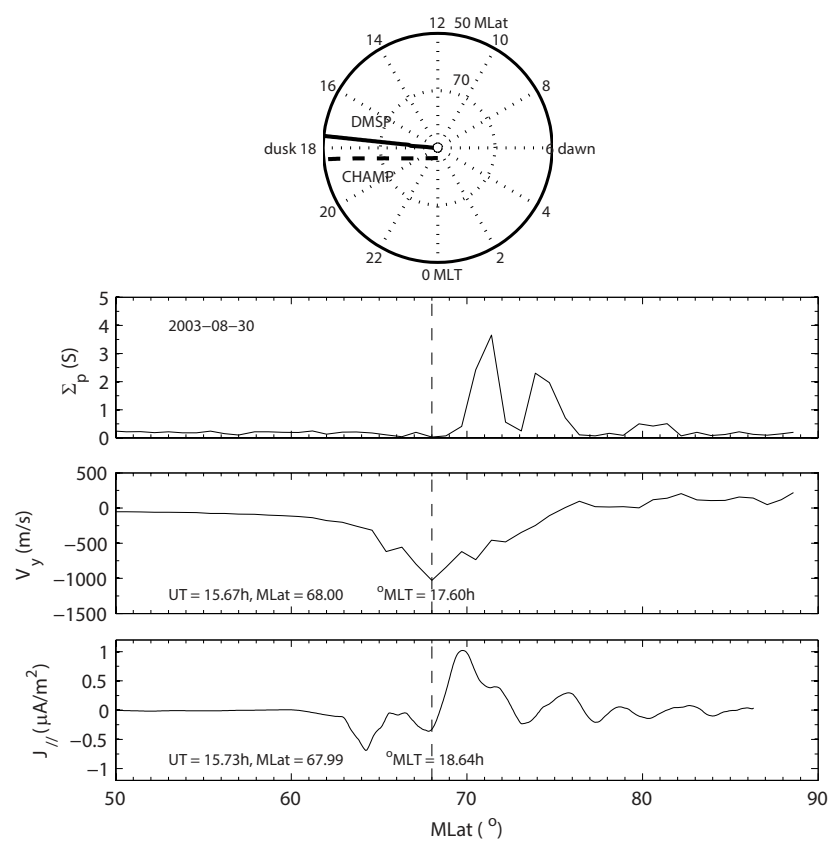

Figure 1. One example of a CHAMP-concurrent orbit in bin 2 (from MLT $_{\text {SAPS }}$ to MLT SAPS $+2 \mathrm{~h}$ ) with respect to DMSP-detected SAPS. From top to bottom are CHAMP and DMSP orbit segments in the ionosphere, ionospheric Pedersen conductivity and the plasma convection velocity in the east-west direction from DMSP, as well as field-aligned currents from CHAMP. The peak velocity of SAPS is indicated by the dashed line. The UT (universal time), MLat, and MLT are listed when DMSP and CHAMP pass the region where SAPS peak.

see a strong westward sunward flow, e.g., SAPS, whose peak velocity is indicated by the vertical dashed line. The downward and upward FACs are R2 and R1 FACs.

The numbers of CHAMP orbits in each bin have been listed in Table 1, which are considered large enough for a statistical study. The average latitudes and magnitudes of SAPS peaks, the prevailing Kp (index) levels and SZA (solar zenith angle) for each bin are listed in Table $1 . \mathrm{Kp}$ is on average a little larger for F13 events than for F14/15. F13 events occur in sunlight while F14/15 mainly in darkness.

\section{Statistical results}

We have taken the location of the SAPS peak velocity as the key latitude $\left(0^{\circ} \delta \mathrm{MLat}\right)$. In comparison the latitudinal profiles of CHAMP FACs are stacked with respect to $0^{\circ} \delta$ MLat over a latitude range from -30 to $20^{\circ}$, then a superposition is performed. Figure 2 shows the mean latitudinal variation of FACs in bin 2 (MLT $\simeq 19.2 \mathrm{~h}$ ) for F13 SAPS events (left). The orbit occurring $1.5 \mathrm{~h}$ before the SAPS key time is the black line, the concurrent orbit is the red line, 1.5 and $3 \mathrm{~h}$ later orbits are the blue and green lines, respectively. The standard deviation of averages are indicated as vertical bars. 
Table 1. The columns from left to right give the numbers of CHAMP orbits, the average spatial location (MLT and MLat) and peak velocity of F13 (14/15) SAPS, and the mean Kp index and SZA in each MLT bin.

\begin{tabular}{lllllll}
\hline F13 (F14/15) & Event no. & MLT $(\mathrm{h})$ & MLat $\left(^{\circ}\right)$ & SAPS velocity $\left(\mathrm{m} \mathrm{s}^{-1}\right)$ & Kp index & SZA $\left(^{\circ}\right)$ \\
\hline Bin 1 & $25(52)$ & $18.1(20.5)$ & $64.5(64.1)$ & $1017(841)$ & $3.3(2.9)$ & $82.3(96.6)$ \\
Bin 2 & $30(64)$ & $18.2(20.4)$ & $64.2(63.6)$ & $875(1036)$ & $3.4(2.9)$ & $82.0(100.1)$ \\
Bin 3 & $25(81)$ & $18.0(20.4)$ & $65.7(63.6)$ & $1177(1184)$ & $3.1(2.8)$ & $86.5(102.9)$ \\
Center & $15(30)$ & $18.3(20.4)$ & $63.7(63.9)$ & $787(766)$ & $3.6(3.0)$ & $75.7(94.5)$ \\
\hline
\end{tabular}
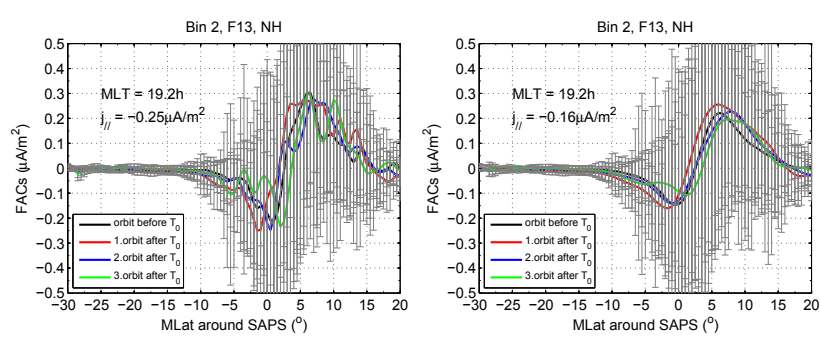

Figure 2. Superposed epoch analysis of large-scale FACs in bin 2 for the DMSP F13 SAPS event (left: 20 s averaged FACs, right: filtered data). Positive denotes upward FACs flowing out of the ionosphere. Black line: orbit arc before SAPS; red line: $0-0.5 \mathrm{~h}$ after SAPS; blue line: $1.5-2 \mathrm{~h}$ after SAPS; green line: $3-3.5 \mathrm{~h}$ after SAPS. Standard deviations are marked by vertical bars.

All four curves show a pair of current sheets, with downward R2 FACs located equatorward and upward R1 FACs poleward, which is a typical configuration in the dusk sector. There are some small current structures overlaid on the two dominant large-scale current sheets. For the determination of the peak of the large-scale currents, it might be more appropriate to used the filtered FACs. After the filter is applied, only the dual-sheet pattern dominates, as shown in the righthand side panel in Fig. 2. In the following the filtered data are presented.

Figure 3 shows the average latitudinal variation of FACs in all local time bins for F13 and F14/15 SAPS events. Bin 1 is centered around $17.2 \mathrm{~h}(19.7 \mathrm{~h})$ MLT, bin 2 around $19.2 \mathrm{~h}$ $(21.7 \mathrm{~h})$ MLT, and bin 3 around 21.6 $\mathrm{h}(23.3 \mathrm{~h})$ MLT for F13 (F14/15) SAPS events. For the F14/15 event in bin 3, the downward FACs are not so obvious, which may be due to a later MLT sector. FAC densities are weaker for F14/15 than for F13 SAPS events because of the differences in both the geomagnetic activity and solar illumination. In all figures the valley shows R2 FACs peaks and the summit as R1 FACs peaks. If the location of R2 FACs is negative, it means the R2 FACs are equatorward of the SAPS, and vice versa. In each local time bin it is obvious that R2 FACs get enhanced at the key time of the SAPS. In the subsequent orbits R2 FACs decay in magnitude and the peak of R2 FACs retreats poleward. The positions of the R2 FAC peaks shift equatorward with increasing MLT.
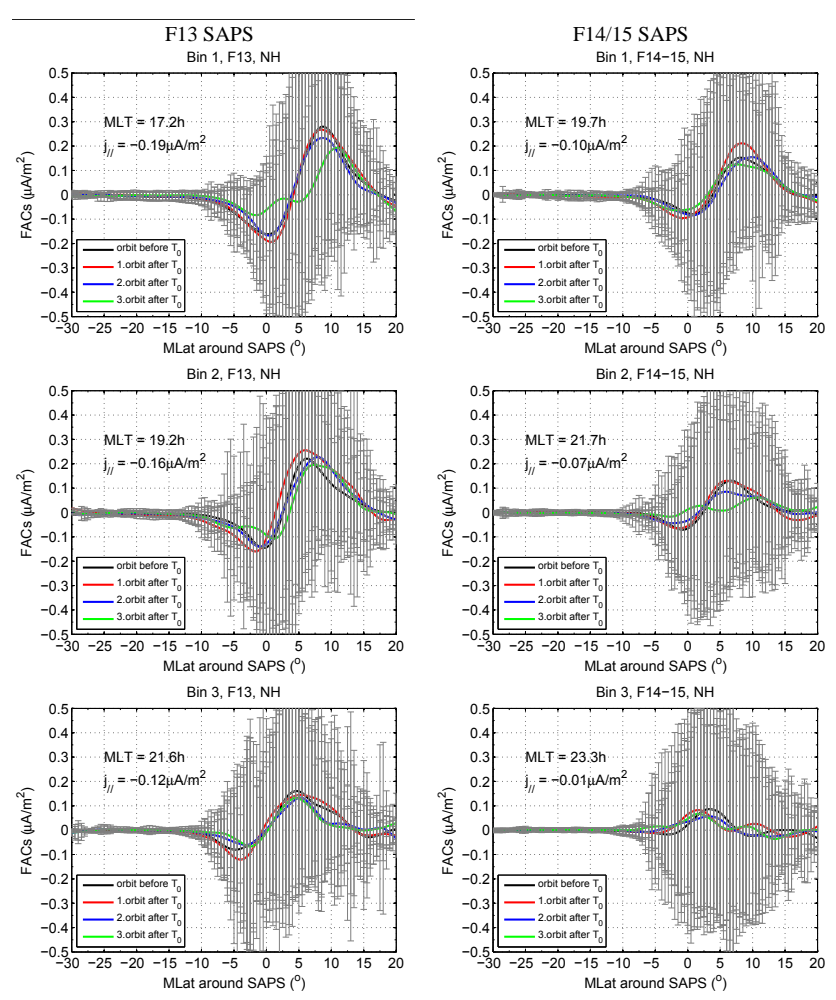

Figure 3. Superposed epoch analysis of large-scale FACs in each bin for DMSP F13 and F14/15.

We also looked at the small- and medium-scale FACs (SSFAC) (10-150 km wavelengths), which are derived from the $1 \mathrm{~Hz}$ preprocessed CHAMP FGM data. Here we calculate the intensity by means of the rms (root mean square) of the SSFAC data in an interval of $11 \mathrm{~s}$ for each point along the satellite orbit. The calculation method has been described in detail in Xiong et al. (2014). The rmd values can be used in the SEA (superposed epoch analysis) in a similar way as the large-scale FACs, as shown in Fig. 4. It is obvious that the amplitude of the SSFAC is much larger than those from the large-scale FACs. This indicates that most of the energy is transported by smaller-scale FACs. It is clear that SSFAC have their peaks poleward of SAPS. The SSFAC get a little enhanced at the time of SAPS occurrence. The intensity of SSFAC is closely related with the ionospheric conductivity distribution (e.g., Wang et al., 2005). 

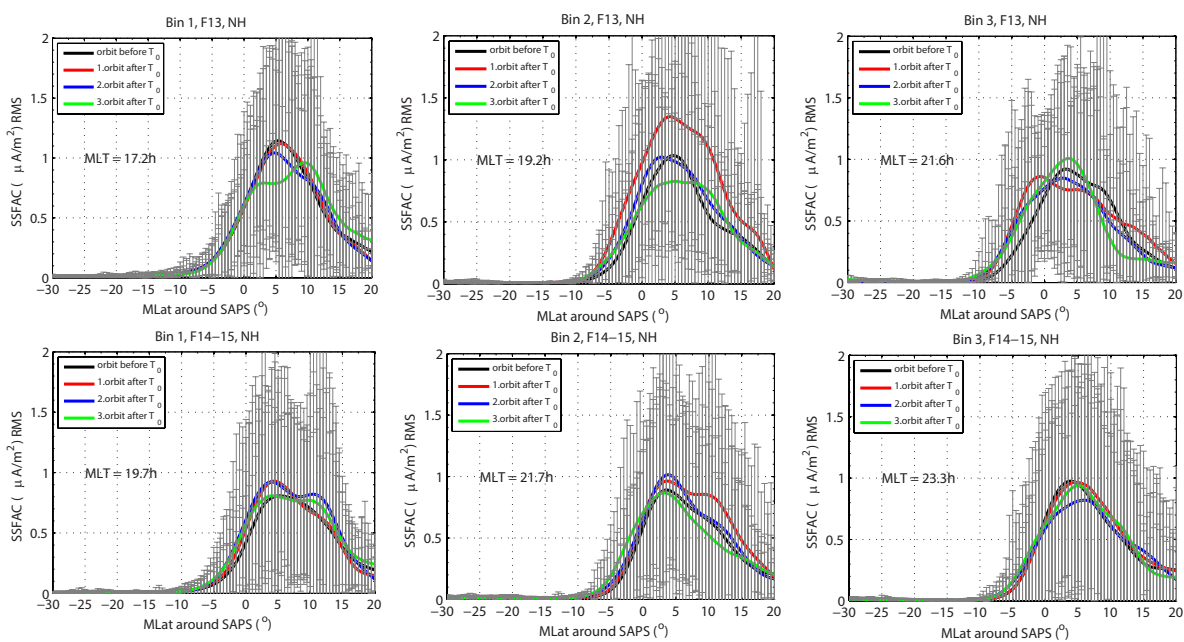

Figure 4. As Fig. 3, but for the intensity of small- and medium-scale FACs (SSFACs).
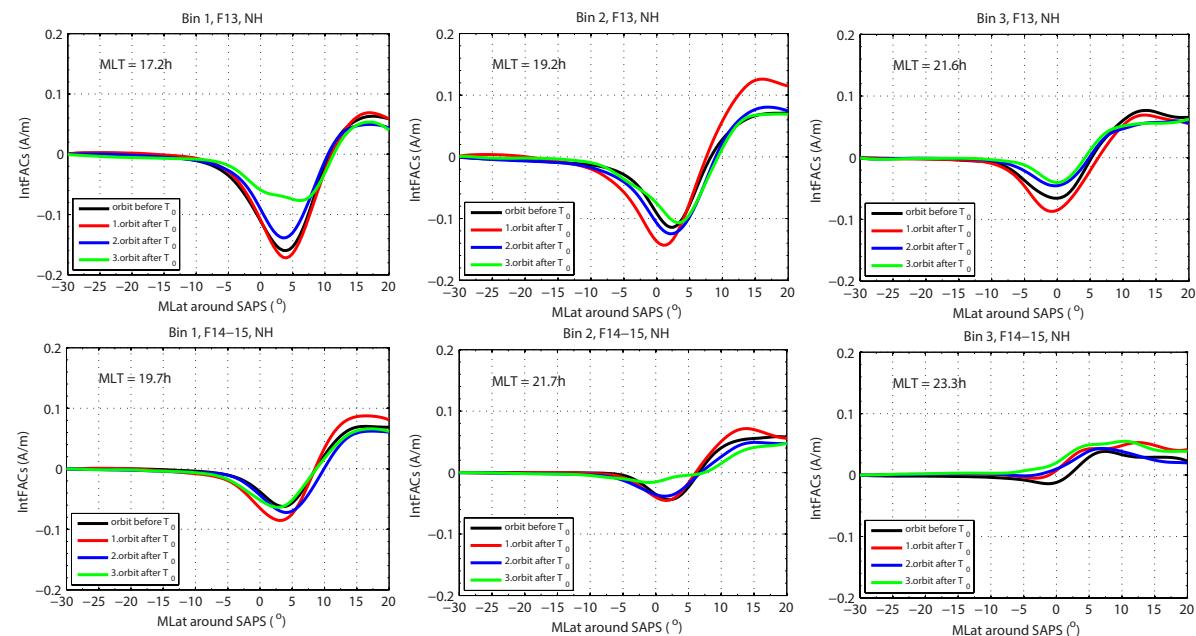

Figure 5. As Fig. 3, but for the integrated FACs.

It might be interesting to see how the total strength of the downward FACs changes when a SAPS occurs. For that we have integrated the FACs (IFACs) along the orbits as IFACs $=\int j_{/ /} \mathrm{ds}$, where ds is the distance along the orbit segment, as presented in Fig. 5. The peak downward IFACs (IR2 FACs) are larger for F13 SAPS than for F14/15. IR2 FACs increase in magnitude when SAPS occur and decrease in the subsequent orbits. Due to both a decrease in current density and width, IR2 FACs decrease with increasing MLT. The position of IR2 FACs can be regarded as the poleward boundary of the R2 FACs, which shifts equatorward for a later MLT. It can be noticed that there are net upward FACs at the end of the orbit segment, which means the upward R1 FACs are not fully balanced by the downward R2 FACs in the duskpremidnight sector. The net upward FACs might close because of Pedersen currents through the polar cap connected to R1 FACs on the dawnside. Previous works have also stated that a net downward FAC exists equatorward and the upward FACs poleward of the SAPS region (e.g., Rich et al., 1980; Figueiredo et al., 2004).

\section{Discussion}

In the previous section we have described the temporal and spatial variation of FACs in association with SAPS. Both the peak value and full strength of R2 FACs get enhanced when SAPS attain peaks, afterwards FACs tend to recover in magnitude and retreat poleward. The presented temporal variation of FACs confirms previous model works claiming that FACs might decay within 37 min after a SAPS occurred, due to the decrease in conductivity (e.g., Banks and Yasuhara, 1978; Rich et al., 1980). The purpose of this work is to determine the relative location of peaks in SAPS and FACs. Previously we have statistically studied the effect of SAPS on 

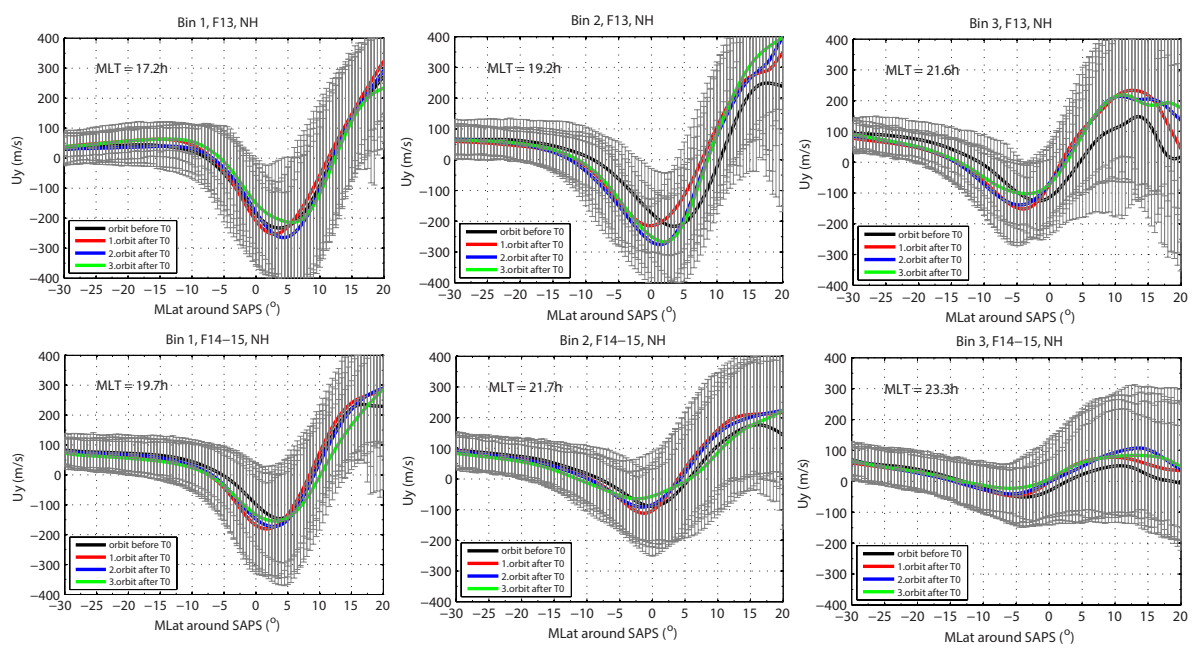

Figure 6. As Fig. 3, but for the zonal wind. Negative denotes westward (sunward) direction.

the zonal wind by using both DMSP and CHAMP satellite observations (Wang et al., 2011). It is shown that both SAPS and zonal wind peak at almost the same position, representing strong effects of SAPS on the zonal wind. Regarding the timescale of ion-neutral coupling, Emmert et al. (2006) found that the response of high-latitude wind to plasma convection is broadly maximized at a time lag of $1 \mathrm{~h}$ at around $250 \mathrm{~km}$ altitude during quiet time. They suggest that the time delay can be further reduced at higher altitude and on the nightside. Previous studies showed that the thermosphere reaction during magnetic storms could be much faster, simultaneously or within $30 \mathrm{~min}$ (e.g Liu et al., 2011). Based on these results, we might use the location of the peak westward zonal wind deduced from CHAMP measurements to refer to the SAPS location in each MLT bin. However, one must keep in mind that there can be errors since measurements have been taken by two different spacecraft and at somewhat different times. Improvements and more complete investigations can be expected from the data of the ESA's (European Space Agency) constellation mission Swarm.

Figure 6 shows the mean latitudinal variation of the zonal wind in the same MLT bin as Fig. 3. It can be seen that the westward zonal wind gets enhanced at the key time of SAPS, and the peak shifts equatorward. Afterwards, the magnitudes decay and the positions retreat poleward. The variations of the zonal wind that center at the sector of $23.2 \mathrm{~h}$ MLT are rather small.

\subsection{Relative positions}

Thereafter we can compare the relative positions of the SAPS peak (represented by the peak in westward zonal wind), the R2 FACs peak, the poleward boundary of the downward current region, and SSFAC peak, as shown in Fig. 7. All parameters are derived for concurrent CHAMP orbits when SAPSs attain peaks (red curves in Figs. 2-5). Parameters in bin 3 for
F14/15 events do not show obvious variations and, thus, they are not shown. It can be seen that the latitudes of four parameters shift equatorward with increasing MLT. Apparently the peak zonal wind (SAPS) is located poleward of the peak of the downward R2 FACs but equatorward of that of the R1 FACs. The fact that SAPS is located near the poleward wall of R2 FACs is consistent with the current-generator model. The gap between the SAPS and R2 FACs decreases with increasing MLT. The peaks of SSFAC are located poleward of SAPS, mainly in the upward R1 FACs domain.

To further validate the above conclusion, we have selected conjugate CHAMP-DMSP observations to directly compare the position of FACs with that of SAPS. For that study we have used events when CHAMP passes the MLat of the peak velocity of SAPS within a zonal segment of $\pm 7.5^{\circ}$ in longitude no later than $30 \mathrm{~min}$ after the SAPS detection time. The number of these observations and related SAPS features (position and magnitude) have been listed at the bottom of Table 1. The average distribution of FACs is shown in Fig. 8. CHAMP is aligned with DMSP in the same MLT sectors, which is on average $18.3 \mathrm{~h}(20.5 \mathrm{~h})$ MLT for F13 (F14/15) SAPS events. It clearly reveals that peak SAPSs are located poleward of the peak of the downward R2 FACs and equatorward of the upward R1 FACs for both F13 and F14/15 cases.

Previous works have studied the relative location of FAC sheets with respect to the equatorward boundary of ion and electron auroras during substorm periods. Klumpar (1979) found that R2 FACs extend on average $2.4^{\circ}$ equatorward of the electron-precipitation boundary. Gussenhoven et al. (1983) reported that the ion-precipitation boundary is $1.4^{\circ}$ equatorward of the electron boundary, the separation often reaches up to 3 and even $5^{\circ}$ in latitude. Our results also imply that the R2 FACs peaks are located equatorward of SAPS peaks, which form well equatorward of the electronprecipitation boundary. 

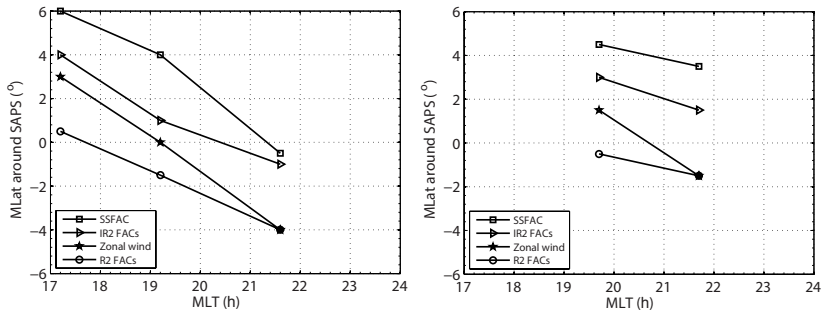

Figure 7. The MLat of peaks in the SSFACs, integrated downward R2 FACs (IR2), westward zonal wind, and downward R2 FACs as a function of MLT during the first orbit after SAPS occurrence.
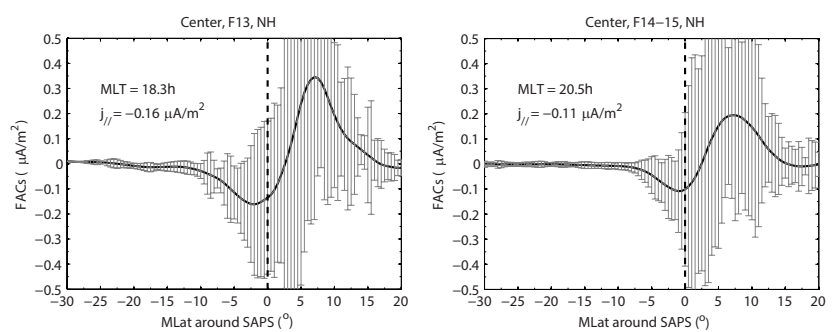

Figure 8. Superposed epoch analysis of FACs centering around F13 and F14/15 SAPS within $\pm 0.5 \mathrm{~h}$ MLT, almost concurrent with SAPS.

\subsection{Model results}

A numerical model has been used to confirm the above result. The electric potential $(\Phi)$ and the radial component of the field-aligned currents $\left(j_{R}\right)$ are connected by the following relationship:

$j_{R}=\nabla_{\perp} \cdot(\Sigma \cdot \nabla \Phi)$,

where $\Sigma$ is the ionospheric-conductance tensor. When assuming that the potential and conductivity are homogeneous in the longitudinal direction, which is common near dusk, and that the field lines are vertical, we can simplify Eq. (1) as (the detailed manipulation can be found in Ridley et al., 2002)

$j_{R}=\frac{1}{R^{2}}\left(\frac{\delta \Sigma_{\mathrm{P}}}{\delta \theta} \frac{\delta \Phi}{\delta \theta}+\Sigma_{\mathrm{P}} \frac{\delta^{2} \Phi}{\delta^{2} \theta}\right)$,

where $\theta$ is colatitude, $R$ is the radial distance from Earth's center, and $\Sigma_{\mathrm{P}}$ is the height-integrated Pedersen conductivity, respectively. The poleward electric field can then be described as $E_{\theta}=-\frac{\delta \Phi}{R \delta \theta}$. For the above relationship it follows that $j_{R}=-\frac{1}{R^{2}}\left(\frac{\delta}{\delta \theta}\left(\Sigma_{\mathrm{P}} E_{\theta}\right)\right)$. This reflects a simple relationship between the northward electric field $\left(E_{\theta}\right)$ and Pedersen conductance $\left(\Sigma_{\mathrm{P}}\right)$. We have used this numerical model previously to investigate the effect of the ionospheric conductivity on the azimuthal plasma flow (Wang et al., 2010).

The auroral Pedersen conductance is assumed to be shaped as a cosine bell superposed on a $1 \mathrm{~S}$ background conductance. For the non-SAPS event, we have assumed that R1
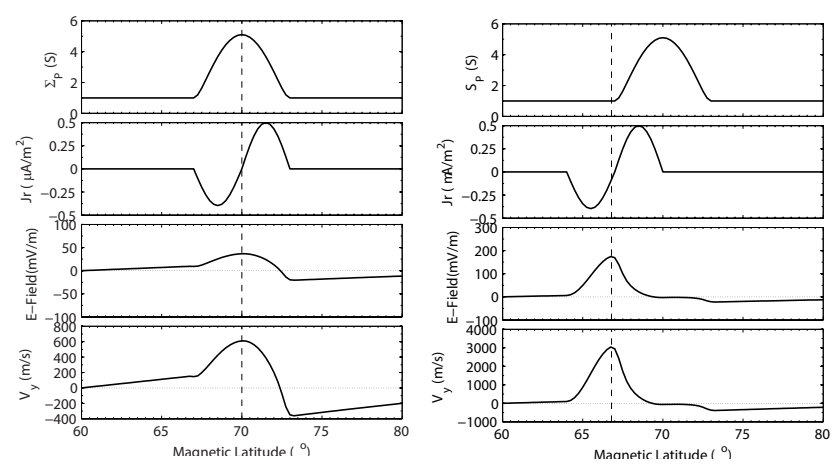

Figure 9. Numerical simulation of high-latitude plasma dynamics. From top to bottom frames show the Pedersen conductivity (sine wave), FACs (sine wave) and the derived electric field (positive denotes poleward) and azimuthal velocity (positive denotes sunward) from Eq. (2).

and R2 FACs on the duskside exhibit a sine-wave shaped latitudinal profile in the auroral region, as shown in the left panel in Fig. 9, while for a SAPS event, we have shifted the R2 FACs to the subauroral region (i.e., low-conductivity area), as shown in the right panel in Fig. 9. The electric field and azimuthal velocity can be solved analytically by using Eq. (2). In Fig. 9, positive values mean upward FACs, poleward (northward) electric field, and westward (sunward) plasma flow. The vertical dashed line marks the peak electric field and velocity.

It can be seen that the poleward electric field and westward plasma flow peak in the auroral zone for non-SAPS events when R2 FACs are located in the auroral zone. When R2 FACs shift equatorward to less conductive regions, both the poleward electric field and the westward plasma flow increase in magnitude with their peaks shifting equatorward but located poleward of the R2 FAC's peak. This is consistent with the presented statistical result that SAPS peaks are located between R1 and R2 FAC peaks, which provides evidence for a current-generator mechanism.

Previous works have implied that SAIDS and SAPS are generated in the same way (e.g., Mishin, 2013). However, SAIDs are more closely associated with substorms (Anderson et al., 1993). Future work might differentiate these two types of events and investigate them separately.

\section{Summary}

We have presented a statistical study of the relative positions of SAPS with respect to large- and small-scale FACs in different MLT sectors by using coordinated observations of CHAMP and DMSP. The observational results have been further confirmed by an analytical model. Both observations and the model's results show evidence in support of a currentgenerator mechanism for SAPS. Some interesting results have been found. 
1. Both the current density and total magnitude (IR2 FACs) of R2 FACs increase when SAPS occur. The current strength decays and the peak retreats poleward in the subsequent orbits. The peak of IR2 FACs decreases with increasing MLT due to a decrease in both the current density and the current width.

2. The latitudes of the peaks of R2 FAC, IR2 FACs, SSFAC, and SAPS shift equatorward with increasing MLT. The latitudinal gap between peaks in SAPS and the R2 FAC decreases with increasing MLT. The peak SAPSs are located between the peaks of R2 and R1 FACs, which is consistent with a current-generator model. The peak SSFAC is located poleward of SAPS, mainly in the upward R1 FAC's region.

3. The upward R1 FACs are not fully balanced by the downward R2 FACs in the dusk-premidnight sector. The net upward FACs seem to partly feed the R1 FACs on the dawn and morning sides.

4. Model results confirm that the westward plasma flow peaks in the auroral zone when the R2 FACs are located in the auroral zone, however, when the R2 FACs shift equatorward to a less conductive region, the westward plasma flow increases in magnitude with its peak shifted equatorward but located poleward of the R2 FAC's peak.

Acknowledgements. The operational support of the CHAMP mission by the German Aerospace Center (DLR) and the financial support for the data processing by the Federal Ministry of Education (BMBF), as part of the Geotechnology Programme, are gratefully acknowledged. We thank the Center for Space Sciences at the University of Texas at Dallas and the US Air Force for providing the DMSP IDM plasma data and the Space Physics Interactive Data Resource (SPIDR) for providing the DMSP SSJ/4 data. The WDC $\mathrm{C} 2$ for Geomagnetism at Kyoto are greatly acknowledged for providing the geomagnetic indices data. This work is supported by the National Nature Science Foundation of China (no. 41222030, 41221003), the Program for Young Excellent Scientist by Organization Department, and the Program for New Century Excellent Talent in University by Ministry of Education, and the Specialized Research Fund for State Key Laboratories.

Topical Editor G. Balasis thanks J. M. Ruohoniemi and X. Cai for their help in evaluating this paper.

\section{References}

Anderson, P. C., Heelis, R. A., and Hanson, W. B.: The ionospheric signatures of rapid subauroral ion drifts, J. Geophys. Res., 96, 5785-5792, 1991.

Anderson, P. C., Hanson, W. B., Heelis, R. A., Craven, J. D., Baker, D. N., and Frank, L. A.: A proposed production model of rapid subauroral ion drifts and their relationship to substorm evolution, J. Geophys. Res., 98, 6069-6078, 1993.
Anderson, P. C., Carpenter, D. L., Tsuruda, K., Mukai, T., and Rich, F. J.: Multisatellite observations of rapid subauroral ion drifts (SAID), J. Geophys. Res., 106, 29585-29600, doi:10.1029/2001JA000128, 2001.

Banks, P. M. and Yasuhara, F.: Electric fields and conductivity in the nighttime E-region - A new magnetosphere-ionosphereatmosphere coupling effect, Geophys. Res. Lett., 5, 1047-1050, doi:10.1029/GL005i012p01047, 1978.

Basu, S., Basu, S., Makela, J. J., MacKenzie, E., Doherty, P., Wright, J. W., Rich, F., Keskinen, M. J., Sheehan, R. E., and Coster, A. J.: Large magnetic storm-induced nighttime ionospheric flows at midlatitudes and their impacts on GPS-based navigation systems, J. Geophys. Res.-Space, 113, A00A06, doi:10.1029/2008JA013076, 2008.

Clausen, L. B. N., Baker, J. B. H., Ruohoniemi, J. M., Greenwald, R. A., Thomas, E. G., Shepherd, S. G., Talaat, E. R., Bristow, W. A., Zheng, Y., Coster, A. J., and Sazykin, S.: Large-scale observations of a subauroral polarization stream by midlatitude $\mathrm{Su}$ perDARN radars: Instantaneous longitudinal velocity variations, J. Geophys. Res., 117, A05306, doi:10.1029/2011JA017232, 2012.

De Keyser, J.: Formation and evolution of subauroral ion drifts in the course of a substorm, J. Geophys. Res., 104, 12339-12350, doi:10.1029/1999JA900109, 1999.

Emmert, J. T., Hernandez, G., Jarvis, M. J., Niciejewski, R. J., Sipler, D. P., and Vennerstrom, S.: Climatologies of nighttime upper thermospheric winds measured by groundbased Fabry-Perot interferometers during geomagnetically quiet conditions: 2. High-latitude circulation and interplanetary magnetic field dependence, J. Geophys. Res., 111, 12303, doi:10.1029/2006JA011949, 2006.

Erickson, P. J., Goncharenko, L. P., Nicolls, M. J., Ruohoniemi, M., and Kelley, M. C.: Dynamics of North American sector ionospheric and thermospheric response during the November 2004 superstorm, J. Atmos. Terr. Phys., 72, 292-301, doi:10.1016/j.jastp.2009.04.001, 2010.

Erickson, P. J., Beroz, F., and Miskin, M. Z.: Statistical characterization of the American sector subauroral polarization stream using incoherent scatter radar, J. Geophys. Res., 116, A00J21, doi:10.1029/2010JA015738, 2011.

Fejer, B. G. and Scherliess, L.: Mid- and low-latitude promptpenetration ionospheric zonal plasma drifts, Geophys. Res. Lett., 25, 3071-3074, doi:10.1029/98GL02325, 1998.

Figueiredo, S., Karlsson, T., and Marklund, G. T.: Investigation of subauroral ion drifts and related field-aligned currents and ionospheric Pedersen conductivity distribution, Ann. Geophys., 22, 923-934, doi:10.5194/angeo-22-923-2004, 2004.

Foster, J. C. and Vo, H. B.: Average characteristics and activity dependence of the subauroral polarization stream, J. Geophys. Res., 107, 1475, doi:10.1029/2002JA009409, 2002.

Foster, J. C., Ericson, P. J., Coster, A. J., Goldstein, J., and Rich, F. J.: Ionospheric signatures of plasmaspheric tails, Geophys. Res. Lett., 29, 1623, doi:10.1029/2002GL015067, 2002.

Foster, J. C., Rideout, W., Sandel, B., Forrester, W. T., and Rich, F. J.: On the relationship of SAPS to stormenhanced density, J. Atmos. Sol.-Terr. Phys., 69, 303-313, doi:10.1016/j.jastp.2006.07.021, 2007. 
Galperin, Y., Ponomarev, V. N., and Zosimova, A. G.: Plasma convection in the polar ionosphere, Ann. Geophys., 30, 1-7, 1974, http://www.ann-geophys.net/30/1/1974/.

Garner, T. W., Wolf, R. A., Spiro, R. W., Burke, W. J., Fejer, B. G., Sazykin, S., Roeder, J. L., and Hairston, M. R.: Magnetospheric electric fields and plasma sheet injection to low L-shells during the 4-5 June 1991 magnetic storm: Comparison between the Rice Convection Model and observations, J. Geophys. Res., 109, A02214, doi:10.1029/2003JA010208, 2004.

Gussenhoven, M. S., Heinemann, N., and Hardy, D. A.: Systematics of the equatorward diffuse auroral boundary, J. Geophys. Res., 88, 5692-5708, doi:10.1029/JA088iA07p05692, 1983.

Hardy, D. A., Schmitt, L. K., Gussenhoven, M. S., Marshall, F. J., and Yeh, H. C.: Precipitating electron and ion detectors (SSJ/4) for the block 5D/Flights 6-10 DMSP (Defense Meteorological Satellite Program) satellites: Calibration and data presentation, Rep. AFGL-TR-84-0314, Air Force Geophys. Lab., Air Force Base, MA, 1984.

Harel, M., Wolf, R. A., Spiro, R. W., Reiff, P. H., Chen, C.K., Burke, W. J., Rich, F. J., and Smiddy, M.: Quantitative simulation of a magnetospheric substorm. II - Comparison with observations, J. Geophys. Res., 86, 2242-2260, doi:10.1029/JA086iA04p02242, 1981.

Jensen, J. W. and Fejer, B. G.: Longitudinal dependence of middle and low latitude zonal plasma drifts measured by DE2, Ann. Geophys., 25, 2551-2559, doi:10.5194/angeo-25-25512007, 2007.

Karlsson, T., Marklund, G. T., and Blomberg, L. G.: Subauroral electric fields observed by the Freja satellite: A statistical study, J. Geophys. Res., 103, 4327-4341, 1998.

Klumpar, D. M.: Relationships between auroral particle distributions and magnetic field perturbations associated with field-aligned currents, J. Geophys. Res., 84, 6524-6532, doi:10.1029/JA084iA11p06524, 1979.

Kunduri, B. S. R., Baker, J. B. H., Ruohoniemi, J. M., Clausen, L. B. N., Grocott, A., Thomas, E. G., Freeman, M. P., and Talaat, E. R.: An examination of inter-hemispheric conjugacy in a subauroral polarization stream, J. Geophys. Res., 117, A08225, doi:10.1029/2012JA017784, 2012

Liemohn, M. W., Ridley, A. J., Brandt, P. C., Gallagher, D. L., Kozyra, J. U., Ober, D. M., Mitchell, D. G., Roelof, E. C., and DeMajistre, R.: Parametric analysis of nightside conductance effects on inner magnetospheric dynamics for the 17 April 2002 storm, J. Geophys. Res., 110, A12S22, doi:10.1029/2005JA011109, 2005.

Liu, R., Ma, S.-Y., and Lühr, H.: Predicting storm-time thermospheric mass density variations at CHAMP and GRACE altitudes, Ann. Geophys., 29, 443-453, doi:10.5194/angeo-29-4432011, 2011.

Lühr, H., Warnecke, J., and Rother, M. K. A.: An algorithm for estimating field-aligned currents from single spacecraft magnetic field measurements: A diagnostic tool applied to Freja satellite data, IEEE T. Geosci. Remote Sens., 34, 1369-1376, 1996.

Maynard, N. C.: On large poleward-directed electric fields at sub-auroral latitudes, Geophys. Res. Lett., 5, 617-618, doi:10.1029/GL005i007p00617, 1978.

Mishin, E. V.: Interaction of substorm injections with the subauroral geospace: 1. Multispacecraft observations of SAID, J. Geophys. Res., 118, 5782-5796, doi:10.1002/jgra.50548, 2013.
Moffett, R. J., Heelis, R. A., Sellek, R., and Bailey, G. J.: The temporal evolution of the ionospheric signatures of subauroral ion drifts, Planet. Space Sci., 40, 663-670, doi:10.1016/00320633(92)90007-B, 1992.

Reigber, C., Lühr, H., and Schwintzer, P.: CHAMP mission status, Adv. Space Res., 30, 129-134, 2002.

Rich, F. J. and Hairston, M.: Large-scale convection patterns observed by DMSP, J. Geophys. Res., 99, 3827-3844, 1994.

Rich, F. J., Burke, W. J., Kelley, M. C., and Smiddy, M.: Observations of field-aligned currents in association with strong convection electric fields at subauroral latitudes, J. Geophys. Res., 85, 2335-2340, doi:10.1029/JA085iA05p02335, 1980.

Richmond, A. D.: Ionospheric Electrodynamics Using Magnetic Apex Coordinates, J. Geophys. Res., 47, 191-212, 1995.

Ridley, A. J., Hansen, K. C., Tóth, G., De Zeeuw, D. L., Gombosi, T. I., and Powell, K. G.: University of Michigan MHD results of the Geospace Global Circulation Model metrics challenge, J. Geophys. Res., 107, 1290, doi:10.1029/2001JA000253, 2002.

Robinson, R. M., Vondrak, R. R., Miller, K., Dabbs, T., and Hardy, D. A.: On calculating ionospheric conductances from the flux and energy of precipitating electrons, J. Geophys. Res., 92, 25652569, 1987.

Rowland, D. E. and Wygant, J. R.: Dependence of the large-scale, inner magnetospheric electric field on geomagnetic activity, J. Geophys. Res., 103, 14959-14964, doi:10.1029/97JA03524, 1998.

Scherliess, L. and Fejer, B. G.: Satellite studies of mid- and lowlatitude ionospheric disturbance zonal plasma drifts, Geophys. Res. Lett., 25, 1503-1506, doi:10.1029/98GL01032, 1998.

Smiddy, M., Sagalyn, R., Shuman, B., Kelley, M. C., Burke, W., Rich, F., Hays, R., and Lai, S.: Intense poleward-directed electric fields near the ionospheric projection of the plasmapause, Geophys. Res. Lett., 4, 543-546, doi:10.1029/GL004i011p00543, 1977.

Southwood, D. J. and Wolf, R. A.: An assessment of the role of precipitation in magnetospheric convection, J. Geophys. Res., 83, 5227-5232, 1978.

Spiro, R. W., Heelis, R. A., and Hanson, W. B.: Ion convection and the formation of the mid-latitude $\mathrm{F}$ region ionization trough, J. Geophys. Res., 83, 4255-4264, 1978.

Spiro, R. W., Heelis, R. H., and Hanson, W. B.: Rapid sub-auroral ion drifts observed by Atmospheric Explorer C, Geophys. Res. Lett., 6, 657-660, 1979.

Wang, H. and Lühr, H.: Seasonal variation of the ion upflow in the topside ionosphere during SAPS (subauroral polarization stream) periods, Ann. Geophys., 31, 1521-1534, doi:10.5194/angeo-311521-2013, 2013.

Wang, H., Lühr, H., and Ma, S. Y.: Solar zenith angle and merging electric field control of field-aligned currents: A statistical study of the southern hemisphere, J. Geophys. Res., 110, A03306, doi:10.1029/2004JA010530, 2005.

Wang, H., Lühr, H., Ma, S. Y., Weygand, J., Skoug, R. M., and Yin, F.: Field-aligned currents observed by CHAMP during the intense 2003 geomagnetic storm events, Ann. Geophys., 24, 311324, doi:10.5194/angeo-24-311-2006, 2006.

Wang, H., Lühr, H., Ridley, A., Ritter, P., and Yu, Y.: Storm time dynamics of auroral electrojets: CHAMP observation and the Space Weather Modeling Framework comparison, Ann. Geophys., 26, 555-570, doi:10.5194/angeo-26-555-2008, 2008. 
Wang, H., Lühr, H., and Ridley, A. J.: Plasma convection jets near the poleward boundary of the nightside auroral oval and their relation to Pedersen conductivity gradients, Ann. Geophys., 28, 969-976, doi:10.5194/angeo-28-969-2010, 2010.

Wang, H., Lühr, H., Häusler, K., and Ritter, P.: Effect of subauroral polarization streams on the thermosphere: A statistical study, J. Geophys. Res., 116, A03312, doi:10.1029/2010JA016236, 2011.

Wang, H., Lühr, H., and Ma, S. Y.: The relation between subauroral polarization streams, westward ion fluxes, and zonal wind: Seasonal and hemispheric variations, J. Geophys. Res., 117, A04323, doi:10.1029/2011JA017378, 2012a.

Wang, H., Lühr, H., Ritter, P., and Kervalishvili, G.: Temporal and spatial effects of subauroral polarization streams on the thermospheric dynamics, J. Geophys. Res., 117, A11307, doi:10.1029/2012JA018067, 2012b.

Wang, W. B., Talaat, E. R., Burns, A. G., Emery, B., Hsieh, S., Lei, J., and $\mathrm{Xu}$, J.: Thermosphere and ionosphere response to subauroral polarization streams (SAPS): Model simulations, J. Geophys. Res., 6241, doi:10.1029/2012JA017656, 2012.
Wygant, J., Rowland, D., Singer, H. J., Temerin, M., Mozer, F., and Hudson, M. K.: Experimental evidence on the role of the large spatial scale electric field in creating the ring current, J. Geophys. Res., 103, 29527-29544, doi:10.1029/98JA01436, 1998.

Xiong, C., Lühr, H., Wang, H., and Johnsen, M. G.: Determining the boundaries of auroral oval from CHAMP field-aligned currents signatures, Ann. Geophys., in press, 2014.

Yeh, H.-C. and Foster, J. C.: Storm time heavy ion outflow at mid-latitude, J. Geophys. Res., 95, 7881-7891, doi:10.1029/JA095iA06p07881, 1990.

Yeh, H.-C., Foster, J. C., Rich, F. J., and Swider, W.: Storm time electric field penetration observed at mid-latitude, J. Geophys Res., 96, 5707-5721, 1991.

Zheng, Y., Brandt, P. C., Lui, A. T., and Fok, M. C.: On ionospheric trough conductance and subauroral polarization streams: simulation results, J. Geophys. Res., 113, A04209, doi:10.1029/2007JA012532, 2008. 